\title{
Vegetations in infective endocarditis Clinical relevance and diagnosis by cross sectional echocardiography
}

\author{
WAYNE J STAFFORD, „ JOAN PETCH, DOROTHY J RADFORD \\ From the Department of Cardiology, The Prince Charles Hospital, Brisbane, Queensland, Australia
}

SUMMARY Cross sectional echocardiography identified vegetations in 45 of 62 (73\%) patients who had clinical evidence of active infective endocarditis. The sensitivity of this technique in diagnosing vegetations in infective endocarditis was $93 \%$ and the specificity $89 \%$. The predictive value of a positive test was $96 \%$ and that of a negative test $80 \%$. Vegetations were detected with a similar frequency on the aortic and mitral valves. The incidence of valvar incompetence, congestive heart failure, and the need for surgical intervention was similar in the patients with and without vegetations. Embolism occurred in $47 \%$ of those patients with vegetations and in $12 \%$ of those without. The mortality rate was $27 \%$ in those with vegetations, and no patient without vegetations died.

Thus cross sectional echocardiography is accurate in diagnosing vegetations in patients with infective endocarditis, and this finding identifies patients at high risk of embolic complications and death.

Some patients with infective endocarditis have vegetations which may be identified by echocardiography, and this finding has been suggested to indicate a poor prognosis with a high incidence of complications. ${ }^{1-3}$ Initial studies were, however, performed using $M$ mode echocardiography,,$^{1-3}$ and this is less sensitive than cross sectional echocardiography in detecting smaller or anatomically less accessible vegetations. ${ }^{4-6}$ Few studies have been carried out that reassess the clinical significance of vegetations detected by wide angle cross sectional echocardiography, 257 and the surgical implications of this finding therefore remain controversial. The reliability of detecting vegetations by cross sectional echocardiography also requires careful assessment, as the differentiation of vegetations from other valvar abnormalities by $M$ mode echocardiography is difficult. ${ }^{8}$ In this study we attempted to solve these problems firstly by reviewing our experience of the accuracy of diagnosis of vegeta-

Requests for reprints to Dr Dorothy J Radford, Deparment of Cardiology, The Prince Charles Hospital, Chermside, Queensland, Australia 4032.

*Present address: Division of Cardiology, University of Miami, School of Medicine (D-39), PO Box 016960, Miami, Florida 33101, USA.

Accepted for publication 14 November 1984 tions by cross sectional echocardiography, and, secondly, by determining the relation between the presence of vegetations and the occurrence of clinical complications in patients with active infective endocarditis.

\section{Patients and methods}

Sixty two consecutive patients (42 male, 20 female; mean age 43.8 (range 3-81) years) with the clinical evidence of infective endocarditis underwent cross sectional and $M$ mode echocardiography between December 1979 and May 1983. Follow up was for a mean of 17 (range 1-42) months. All patients had strong clinical evidence of active endocarditis, including two or more of the following features: fever, sweating, heart murmur, splenomegaly, peripheral features of endocarditis, and positive blood cultures. All echocardiographic studies were performed in the standard views during the period of diagnosis and treatment in hospital using a Varian V-3000 (Varian Associates) phased array ultrasonograph. Vegetations were defined as masses, sessile or pedunculated, attached to the cardiac valves or endocardial surfaces. $^{9}$

The clinical records and echocardiographs were reviewed retrospectively and the accuracy of the diag- 


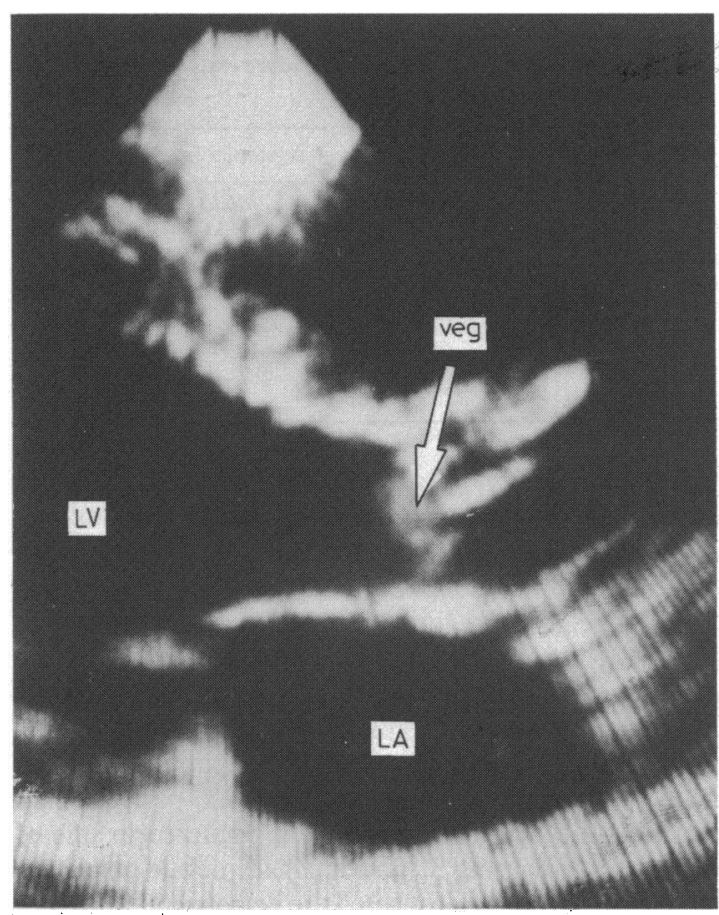

Figure Cross sectional echocardiogram in the pertustermal long axis view showing large vegetations (arrow) attached to the aortic valve leaflets. Veg, vegetations; $L V$, left ventíicle; $L A$, left atrium.

Table 1 Site affected by infectiverendocarditis in 62 patients with and without vegetations

\begin{tabular}{lll}
\hline Site & $\begin{array}{l}\text { With vegetations } \\
(n=45)\end{array}$ & $\begin{array}{l}\text { Without vegetations } \\
(n=17)\end{array}$ \\
\hline Aortic valve & 21 & 11 \\
Mitral valve & 20 & 5 \\
Tricuspid valve & 2 & 0 \\
Pulmonary valve & 0 & 1 \\
Ventricular septal defect & 2 & 0 \\
\hline
\end{tabular}

Table 2 Underlying pathology predisposing to infective endocarditis. Figures are numbers of patients

\begin{tabular}{lll}
\hline Pathology & $\begin{array}{l}\text { With } \\
\text { vegetations } \\
(n=45)\end{array}$ & $\begin{array}{l}\text { Without } \\
\text { vegetations } \\
(n=17)\end{array}$ \\
\hline Mitral valve prolapse & 9 & 3 \\
Bicuspid aortic valve & 8 & 3 \\
Rheumatic aortic valve disease & 2 & 1 \\
Rheumatic mitral valve disease & 2 & 1 \\
Mitral valve disease (other) & 3 & 0 \\
Calcific aortic stenosis & 2 & 3 \\
Aortic valve replacement & 1 & 4 \\
Mitral valve replacement & 2 & 1 \\
Ventricular septal defect & 2 & 0 \\
Congenital subvalvar aortic & 1 & 0 \\
stenosis & 0 & 1 \\
Congenital pulmonary stenosis & 13 & 0 \\
No underlying pathology & 13 & \\
\hline
\end{tabular}

nosis of vegetations by echocardiography assessed by comparing the echocardiographic interpretation with subsequent surgical and necropsy reports of the valvar pathology. The sensitivity, specificity, and diagnostic accuracy of cross sectional echocardiography in detecting vegetations in patients with endocarditis were calculated by the following formulae ${ }^{10}$ : sensitivity $=\mathrm{TP} /(\mathrm{TP}+\mathrm{FN}), \quad$ specificity $=\mathrm{TN} /(\mathrm{TP}+$ FP), diagnostic accuracy of a positive test $=T P /$ (TP+FP), and the diagnostic accuracy of a negative test $=\mathrm{TN} /(\mathrm{TN}+\mathrm{FN})$, where $\mathrm{TP}$ is a true positive, $\mathrm{TN}$ a true negative, FP a false positive, and $\mathrm{FN}$ a false negative test.

The subsequent clinical course and occurrence of complications were also noted and compared with the echocardiographic features. The results were analysed using Fisher's exact probability test for statistical significance.

\section{Results}

Of the 62 patients with active endocarditis, 45 (73\%) had vegetations identified by cross sectional echocardiography (Figure), and 17 (27\%) had no evidence of vegetations. In two patients, vegetations were noted two and four weeks respectively after an initial echocardiogram had shown no evidence of vegetations. In 27 patients, the echocardiographic diagnosis of vegetations was subsequently confirmed at surgery or necropsy. Two patients had vegetations which were missed by echocardiography, and one patient had thickened aortic valve leaflets incorrectly diagnosed as vegetations. Eight patients were confirmed as having no evidence of vegetations on echocardiography or at surgery (true negative test). In 24 patients there was no confirmation of the presence or absence of vegetations.

Using the standard formulae, the sensitivity of cross sectional echocardiography in diagnosing vegetations was $93 \%$ and the specificity $89 \%$. The predictive value of a positive test was $96 \%$ and the predictive value of a negative echocardiogram for the absence of vegetations $80 \%$.

The aortic and mitral valves were most commonly affected, with vegetations occurring with similar frequency in either of these positions (Table 1). The underlying pathology predisposing to endocarditis in these patients was similar in patients with vegetations and in those without (Table 2). Three patients had echocardiographic evidence of mitral valve prolapse with redundant leaflet tissue, such that there was difficulty in differentiating coexisting vegetations. In each case, however, there were considered to be vegetations in addition to leaflet tissue, and this was subsequently confirmed at operation in two of the three patients. Other complications were detected by cross 
Table 3 Organisms detected in 62 patients with infective endocarditis. Figures are numbers of patients

\begin{tabular}{lcl}
\hline Organism & $\begin{array}{l}\text { With } \\
\text { vegetations } \\
(n=45)\end{array}$ & $\begin{array}{l}\text { Without } \\
\text { vegetations } \\
(\boldsymbol{n}=17)\end{array}$ \\
\hline Streptococcus viridans & 8 & 6 \\
Streptococcus sanguis & 3 & 1 \\
Streptococcus mitis & 1 & 0 \\
$\alpha$ Haemolytic streptococcus & 3 & 0 \\
Streptococcus faecalis & 1 & 1 \\
Streptococcus bovis & 1 & 0 \\
Staphylococcus aureus & 13 & 2 \\
Staphylococcus epidermidis & 2 & 0 \\
Coxiella burnetii (Q fever) & 3 & 0 \\
Haemophilus infuenzae & 1 & 2 \\
Corynebacterium diptheriae gravis & 1 & 0 \\
Actinobacillus actinomycetemcomitans & 1 & 0 \\
Paecilomyces varioti (fungal) & 1 & 0 \\
Culture negative & 6 & 5 \\
\hline
\end{tabular}

sectional echocardiography including pericardial effusion in 11 patients, para-annular aortic abscesses in two, and an aortic false aneurysm in one.

Table 3 shows the organisms detected. Staphylococcus aureus was more common in the group of patients with vegetations. The other organisms were similar in those with and without vegetations.

Table 4 shows the incidence of clinical complications in these patients. The indications for surgery in all cases were progressive valvar incompetence, severe or refractory heart failure, or uncontrolled infection despite adequate antibiotic treatment. Aortic valve replacement was performed in 25 patients, and mitral valve replacement in nine. Medical treatment alone was successful in eight of the 17 patients $(47 \%)$ without vegetations but in only 12 of $45(27 \%)$ with vegetations $(p=0.09)$.

Embolism occurred from the aortic valve in 11 and from the mitral valve in nine. Nine of the 23 patients with embolism had Staph aureus infection, including four of those who died. The most common site of embolism was cerebral (12 patients) followed by coronary and renal (five each), and three patients with right heart endocarditis had multiple septic pulmonary emboli. The overall mortality rate was $19 \%$, all deaths occurring in the group with vegetations. Eight of the 12 deaths were directly related to systemic embolism. Four deaths occurred in the group that was

Table 4 Incidence of complications in 62 patients with infective endocarditis. Figures are numbers (\%) of patients

\begin{tabular}{llll}
\hline Complication & $\begin{array}{l}\text { With } \\
\text { vegetations } \\
(n=45)\end{array}$ & $\begin{array}{l}\text { Without } \\
\text { vegetations } \\
(n=17)\end{array}$ & p value \\
\hline Valvar incompetence & $40(89)$ & $15(88)$ & NS \\
Congestive heart failure & $26(58)$ & $9(53)$ & NS \\
Embolism & $21(47)$ & $2(12)$ & $<0.01$ \\
Death & $12(27)$ & 0 & $<0.02$ \\
Need for surgery & $24(53)$ & $9(53)$ & NS \\
\hline
\end{tabular}

NS, not significant.
Table 5 Relation of size of vegetation with clinical complications in 45 patients with vegetative endocarditis. Figures are numbers of patients

\begin{tabular}{llll}
\hline Complication & \multicolumn{3}{l}{ Size of vegetation $(\mathrm{mm})$} \\
\cline { 2 - 4 } & $\begin{array}{l}\text { Small } \\
(\leqslant 5)\end{array}$ & $\begin{array}{l}\text { Moderate } \\
(6-19)\end{array}$ & $\begin{array}{l}\text { Large } \\
(\geqslant 20)\end{array}$ \\
& $(n=4)$ & $(n=25)$ & $(n=16)$ \\
\hline Valvar incompetence & 3 & 23 & 14 \\
Congestive cardiac failure & 1 & 15 & 10 \\
Embolism & 0 & 12 & 9 \\
Death & 0 & 7 & 5 \\
Need for surgery & 2 & 12 & 10 \\
\hline
\end{tabular}

treated surgically. Two patients sustained cerebral emboli at the time of operation, and both subsequently died. Two patients died postoperatively with disseminated coagulopathy and renal failure.

The size of the vegetation on echocardiography was related to the major complications (Table 5). In the group with vegetations, embolism or a fatal outcome in our series occurred only in patients with a vegetation $>5 \mathrm{~mm}$ in diameter, though two patients without vegetations had systemic emboli. Six patients had sessile vegetations, and embolism occurred in one of these; the remaining 39 patients had mobile pedunculated vegetations. Because of the retrospective nature of this study the size of the vegetations estimated echocardiographically and at surgery or necropsy could not be compared. Nevertheless, in all cases in which there was confirmation of the vegetation available the location and morphology of the vegetation were accurate.

\section{Discussion}

The incidence of vegetations in $73 \%$ of the patients in our study resembles closely that reported in other studies using cross sectional echocardiography ${ }^{4} 511$ and is higher than that reported using $M$ mode echocardiography. 146 The difference in the results of the two methods is most likely to be related to the higher sensitivity of cross sectional echocardiography in detecting smaller and less accessible vegetations, a view shared by others. ${ }^{4-6}$ Although somewhat limited by the relatively small number of patients in the present study, the specificity, sensitivity, and diagnostic accuracy support the concept that cross sectional echocardiography is reliable and accurate in detecting vegetations in patients who have active endocarditis. The site and morphology of vegetations seen by echocardiography were related closely to the surgical and necropsy findings. In the two patients who had vegetations missed by echocardiography, one had undergone the investigation six weeks before operation, and thus the vegetations may have developed during this interval; in the other there were abnormal, 
thickened, fibrotic aortic valve leaflets that made the vegetations difficult to identify. A further patient had thickened calcified aortic valve leaflets that were mistaken for vegetations. Three patients had mitral valve prolapse with redundant leaflet tissue in whom the identification of separate vegetations was difficult, a problem also experienced by others. ${ }^{12} 13$

Cross sectional echocardiography was useful not only in detecting vegetations but also in diagnosing other cardiac complications of infective endocarditis including pericardial effusion and aortic para-annular abscesses. The assessment of left ventricular dimensions and function was also of major benefit in assessing haemodynamic function and frequently averted the need for preoperative cardiac catheterisation in this group of critically ill patients.

Vegetations were found with a similar frequency on the aortic and mitral valves, and complications from either site occurred equally. This contrasts with the findings of Come et al, who found a higher incidence of complications from aortic vegetations, ${ }^{14}$ though this was not the experience of others. ${ }^{127}$ The organisms detected were similar in patients with and without vegetations, apart from the higher incidence of Staph aureus in those with vegetations. Takeda et al reported a similar finding. ${ }^{5}$

The incidence of valvar incompetence, congestive heart failure, and the need for surgical intervention was similar in patients with and without vegetations. Lutas et al also found a similar incidence of these complications in the two groups in their series of 77 patients. ${ }^{7}$ This contrasts with several previous studies that reported a higher prevalence of these complications in patients who had vegetations. ${ }^{1-3}$ This difference could be explained by the suggestion that cross sectional echocardiography is more sensitive in detecting smaller and anatomically less accessible vegetations, which are less likely to cause valve destruction and the consequent haemodynamic disturbances. We cannot exclude, however, the possibility that differences in referral patterns or in patient populations may be responsible for the variation in the results of these studies.

The incidence of embolism and the mortality rate were both related to the presence of vegetations on echocardiography, a finding shared with several previous studies. ${ }^{35}{ }^{14}$ Almost half the patients with vegetations in our series subsequently had emboli, and the majority of deaths were directly related to systemic embolism (eight of 12). The size of the vegetations was also relevant in that no emboli occurred in patients who had a vegetation that was $\leqslant 5 \mathrm{~mm}$, though two patients had no vegetations and suffered emboli. The morphology of the vegetations was much less helpful in predicting complications. Medical treatment alone was successful less often in those with vegetations (29\%) than in those without (47\%), though this difference was not statistically significant. In the group with vegetations, 19 patients who suf- fered emboli did so during medical treatment, and six of these subsequently underwent valve replacement. Two patients treated surgically had emboli perioperatively that were possibly related to dislodgement of vegetative material during excision of the infected valve. Thus medical treatment was more likely to be complicated by embolism. Four deaths occurred in the surgically treated group of 24 patients compared with eight in the 21 patients treated medically.

These findings considered together suggest that the presence of large vegetations detected by cross sectional echocardiography identifies patients with infective endocarditis who have a high incidence of embolic complications and death. We recommend that early surgery is considered in patients with infective endocarditis and large vegetations in view of this high risk of embolism. The decision regarding surgery, will, however, remain an individual one based on all the clinical aspects of each case.

\section{References}

1 Davis RS, Strom JA, Frishman W, et al. The demonstration of vegetations by echocardiography in bacterial endocarditis. $A m \mathcal{F}$ Med 1980; 69: 57-63.

2 Stewart JA, Silimperi D, Harris P, Wise NK, Fraker TD Jr, Kisslo JA. Echocardiographic documentation of vegetative lesions in infective endocarditis: clinical implications. Circulation 1980; 61: 374-80.

3 Hickey AJ, Wolfers J, Wilcken DEL. Reliability and clinical relevance of detection of vegetations by echocardiography in bacterial endocarditis. Br Heart $\mathcal{f}$ 1981; 46: 624-8.

4 Martin RP, Meltzer RS, Chia BL, Stinson EB, Rakowski H, Popp RL. Clinical utility of two dimensional echocardiography in infective endocarditis. Am $\mathcal{F}$ Cardiol 1980; 46: 379-85.

5 Takeda P, Skalsky L, Bommer WJ, et al. Two-dimensional echocardiography in infective endocarditis: early and late diagnostic, therapeutic and prognostic implications [Abstract]. Circulation 1980; 62 (suppl III): 99.

6 Melvin ET, Berger M, Lutzker LG, Goldberg E, Mildvan D. Non-invasive methods for detection of valve vegetations in infective endocarditis. Am f Cardiol 1981; 47: 271-8.

7 Lutas EM, Roberts RB, Devereux RB, Prieto LM. Predictive value of echocardiography in endocarditis [Abstract]. Circulation 1983; 68 (suppl III): 364

8 Markiewicz W, Peled B, Alroy G, et al. Echocardiography in infective endocarditis. Lack of specificity in patients with valvular pathology. Eur 7 Cardiol 1979; 10: 247-57.

9 Gilbert BW, Haney RS, Crawford F, et al. Two dimensional echocardiographic assessment of vegetative endocarditis. Circulation 1977; 55: 346-53.

10 Feinstein AR. Clinical biostatistics XXXI. On the sensitivity, specificity and discrimination of diagnostic tests. Clin Pharmacol Ther 1975; 17: 104-16.

11 Wann LS, Hallam CC, Dillon JC, Weyman AE, Feigenbaum H. Comparison of $\mathrm{M}$-mode and cross-sectional echocardiography in infective endocarditis. Circulation 1979; 60: 728-33.

12 Chandraratna PAN, Langevin E. Limitations of the echocardiogram in diagnosing valvular vegetations in patients with mitral valve prolapse. Circulation 1977; 56: 436-8.

13 Hickey AJ, Wolfers J. False positive diagnosis of vegetations on a myxomatous mitral valve using two-dimensional echocardiography. Aust NZ F Med 1982; 12: 540-2.

14 Come PC, Isaacs RE, Riley MF. Diagnostic accuracy of M-mode echocardiography in active infective endocarditis and prognostic implications of ultrasound-detectable vegetations. Am Heart $\mathcal{f}$ 1982; 103: 839-47. 